\title{
Role of Fine Needle Aspiration Cytology in the Diagnosis of Parotid Gland Tumors: Analysis of 193 Cases
}

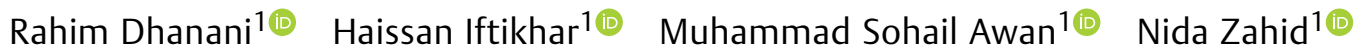 \\ Sehrish Nizar Ali Momin² (iD \\ ${ }^{1}$ Department of Otolaryngology/Head and Neck Surgery at the \\ University Hospital, Aga Khan University Hospital, Karachi, Pakistan \\ 2 Section of Post Graduate Medical Education, Aga Khan University \\ Hospital, Karachi, Pakistan \\ Address for correspondence Haissan Iftikhar, MBBS, FCPS, MSc, \\ Department of Surgery, Aga Khan University Hospital, Main Stadium \\ road, Karachi, Pakistan 74800 (e-mail: haissaniftikhar@gmail.com). \\ Int Arch Otorhinolaryngol 2020;24(4):e508-e512.
}

\section{Abstract}

\section{Keywords}

- parotid tumor

- fine needle aspiration

- cytology

- parotidectomy

- diagnostic accuracy

Introduction Parotid gland tumors include a wide variety of inflammatory and neoplastic diseases. The majority of these tumors are benign (80\%), which usually require superficial parotidectomy, while the incidence of malignant tumors is lower (20\%), requiring more radical surgery with or without neck dissection. The diagnosis cannot be established on the basis of clinical history and simple physical examination and requires complementary diagnostic methods. Fine needle aspiration cytology (FNAC) guided by ultrasound is a widely used diagnostic tool to evaluate parotid swellings.

Objective To determine the sensitivity, specificity, positive and negative predictive values and diagnostic accuracy of FNAC in the diagnosis of parotid gland tumors.

Methods A retrospective chart review of 193 patients who underwent preoperative FNAC and parotidectomy at the Aga Khan University Hospital, Karachi, Pakistan, from the period of January 2000 to December 2015 was performed.

Results Out of 193 patients undergoing parotidectomy, 110 (57\%) were males and 83 (43\%) were females, the mean age being 48.21 and 43.76 years old, respectively. The mean duration of the symptoms was 41.33 months, and the most common symptom was preauricular swelling present in all patients, followed by pain, which was present in 29 patients (15\%) and facial nerve weakness in 6 patients (3.1\%). Fine needle aspiration cytology was performed preoperatively and the results were compared with the final histopathology, which showed sensitivity of $88.9 \%$, specificity of $97.9 \%$, positive predictive value of $93 \%$, negative predictive value of $96.7 \%$ and diagnostic accuracy of $95.8 \%$.

Conclusion Our results suggest that FNAC is relatively an accurate method for preoperative diagnosis of parotid swelling and can prove to be a valuable tool for preoperative counseling of the nature of the disease and prognosis.
\end{abstract}

received

June 21, 2019

accepted

January 19, 2020
DOI https://doi.org/

10.1055/s-0040-1709111. ISSN 1809-9777.
Copyright $\odot 2020$ by Thieme Revinter

Publicações Ltda, Rio de Janeiro, Brazil
License terms

$(\circledast) \Theta \circledast$ 


\section{Introduction}

Salivary gland tumors are a rare entity and account for between $\sim 3$ and $10 \%$ of head and neck tumors and up to $0.6 \%$ of all tumors of the human body. ${ }^{1,2}$ A total of $80 \%$ of the salivary gland tumors involve the parotid gland, and $80 \%$ of these tumors are benign. ${ }^{3}$

The World Health Organization (WHO) has classified parotid tumors as epithelial and nonepithelial tumors. Although this classification is complex, it has been widely accepted across the world because of its advantages regarding the prognostic and therapeutic aspects as, biologically, each tumor behaves differently from another. ${ }^{4}$

The diagnosis of salivary gland tumors is becoming increasingly difficult due to the presence of a large histological variety of benign and malignant tumors and to the lack of specific tumor markers. However, on the other hand, these tumors are easily accessible and are very good targets for fine needle aspiration. ${ }^{4}$

Fine needle aspiration cytology (FNAC) is a simple and useful diagnostic modality in the preoperative assessment of parotid swellings. The history of FNAC goes back to the 1920s at the time of World War I, when it came into use simultaneously in United States and Europe. ${ }^{5,6}$ It is a cytological diagnostic method that is based on the morphology of a cell or group of cells and microparticles of a tissue that are acquired using a needle.

Traditional open biopsy of parotid tumors is no longer used due to high chances of tumor spillage and injury to the facial nerve. ${ }^{7}$ In comparison to this, FNAC is an easily done procedure with minimum risks of complications and no risk of implantation of tumor cells. ${ }^{4,8}$

Authors have claimed FNAC to be an accurate, cost-effective and safe procedure. ${ }^{9,10}$ However, some of the authors were of an opinion that it has little influence on the clinical management. ${ }^{11}$ It helps to differentiate between inflammatory conditions, which may not require surgery, and neoplastic, benign and malignant, which allows to plan properly before any treatment. ${ }^{10}$ Also, if the pathology is known preoperatively, counselling of the patient and the planning of the surgery becomes much easier. ${ }^{5}$

The effectiveness of FNAC of parotid tumors is controversial due to the distinct morphology of the parotid gland. Lower ranges of sensitivity and negative predictive value (NPV) can be related to the difficulty in diagnosis of low grade carcinomas, mostly because of complex cell morphology. ${ }^{10,12,13}$ However, the use of ultrasound (US) increases the accuracy by helping to avoid necrotic and cystic areas and enables to target areas of higher yield. ${ }^{14}$

In the present study, we describe our experience on the usefulness and accuracy of FNAC in the diagnosis of parotid gland tumors.

\section{Objective}

The objective of the present study was to determine the sensitivity, specificity, positive and negative predictive values and diagnostic accuracy of FNAC in the diagnosis of parotid gland tumors.

\section{Methodology}

After receiving exemption from the ethical review committee, a cross-sectional study was conducted at a private tertiary care center of Karachi, Pakistan. The medical records of patients who underwent parotidectomy from the period of January 2000 to December 2015 were reviewed.

A total of 290 parotidectomies with or without neck dissections were performed over the period of 15 years. Of these, 193 patients were included in the present study, in which preoperative FNAC was performed exclusively at our center. The rest of the patients with missing records, previous history of treatment of parotid tumors and preoperative FNAC not performed at our center were excluded from the present study.

In all of the patients, FNAC was performed as a part of the preoperative assessment at our center. It was performed at our pathology department using standard technique. A 22 gauge needle attached to a $10 \mathrm{ml}$ syringe by a free hand technique was used. At least two passes were made in each case to obtain adequate biological material for cytological interpretation. The aspirated material was spread on between 2 and 4 slides and fixed immediately. The slides were stained with the Papanicolaou and occasionally with the May-Grunwald Giemsa methods.

Keeping the final histopathology as a gold standard, we classified our FNAC results into the following categories: true-negative (absence of malignancy correctly diagnosed), true-positive (presence of malignancy correctly diagnosed), false-negative (cytological specimen failed to diagnose a malignancy) and false-positive (cytological specimen was incorrectly considered as malignant).

We compared the final histopathology of the surgical specimen with the preoperative cytology of the FNAC specimen and evaluated the sensitivity, specificity, positive predictive value (PPV), negative predictive value (NPV) and overall diagnostic accuracy of FNAC to differentiate between benign and malignant disease using the Galen and Gambino method.

\section{Results}

There were 110 males and 83 females, with mean ages of 48.2 (standard deviation $[S D] \pm 16.1$ ) and 43.7 (SD \pm 14.7 ) years old, respectively. All of our patients presented with a lump in the parotid region ( $n=193$ ), followed by pain along with a lump, ${ }^{15}$ and 6 patients presented to us with facial nerve weakness along with other 2 symptoms. The mean duration of these symptoms was 41.3 months. The final histological diagnosis of the included cases are listed in - Table 1. A total of 158 patients underwent superficial parotidectomy, whereas total parotidectomy was performed in the remaining 35 patients, out of which 32 also underwent selective neck dissection.

There were 147 (76.1\%) benign and 46 (23.9\%) malignant cases. Pleomorphic adenoma was the most common benign tumor (56.5\%) and mucoepidermoid carcinoma was the most common malignant pathology (12.4\%). Fine needle aspiration cytology smears were nondiagnostic in 8 cases (4.1\%), of which 6 cases were reported as benign ( 4 neoplastic and 2 non neoplastic) and 2 cases turned out to be malignant. 
Table 1 Final histological diagnosis

\begin{tabular}{|l|l|}
\hline Histopathology & Number (n) \\
\hline Pleomorphic adenoma & 109 \\
\hline Warthin tumor & 18 \\
\hline Sialadenitis & 7 \\
\hline Monomorphic adenoma & 5 \\
\hline Tuberculosis & 1 \\
\hline Cyst & 1 \\
\hline Lymph nodes & 6 \\
\hline Myoepithelial carcinoma & 1 \\
\hline Squamous cell carcinoma & 3 \\
\hline Carcinosarcoma & 1 \\
\hline Metastatic melanoma & 1 \\
\hline Dermatofibrosarcoma protuberance & 1 \\
\hline Mucoepidermoid carcinoma & 24 \\
\hline Acinic cell carcinoma & 7 \\
\hline Adenoid cystic carcinoma & 5 \\
\hline Lymphoma & 2 \\
\hline Malignant mixed tumor & 1 \\
\hline Total & 193 \\
\hline
\end{tabular}

Table 2 Histological and cytological diagnosis

\begin{tabular}{|l|l|l|l|}
\hline & Histology & $\begin{array}{l}\text { Cytology } \\
\text { discordant }\end{array}$ & Concordance $\%$ \\
\hline Benign & 147 & $20(13.6 \%)$ & $86.4 \%$ \\
\hline Malignant & 46 & $9(19.6 \%)$ & $80.4 \%$ \\
\hline \multicolumn{2}{|l|}{ Overall concordance } & $85 \%$ \\
\hline
\end{tabular}

Table 3 True positives with inaccurate results

\begin{tabular}{|l|l|}
\hline $\mathbf{n}=\mathbf{4 0}$ & $37(92.5 \%)$ \\
\hline Accurate & $3(7.5 \%)$ \\
\hline Inaccurate & Histological diagnosis $(\mathrm{n})$ \\
\hline Cytological diagnosis $(\mathrm{n})$ & Acinic cell carcinoma $^{1}$ \\
\hline Mucoepidermoid carcinoma $^{1}$ & Adenoid cystic carcinoma $^{1}$ \\
\hline Myoepithelial carcinoma $^{1}$ & Mucoepidermoid carcinoma $^{1}$ \\
\hline Acinic cell carcinoma $^{1}$ &
\end{tabular}

Overall, an $85 \%$ concordance was established between the FNAC and the final histological diagnosis, the breakup of benign and malignant cases is described in - Table 2. The cytological diagnosis was true positive in 40 (20.7\%) cases, and true negative in 145 (75.1\%) cases. Inaccurate cases are mentioned in -Table 3 and 4 . There were 3 (1.5\%) false positive and 5 (2.6\%) false negative cases (-Table 5 ).

The statistical analysis of 193 cases were done to assess the diagnostic accuracy of parotid FNAC compared with the gold standard final histological result ( - Table 6). A sensitiv-
Table 4 True negative with inaccurate results

\begin{tabular}{|c|c|}
\hline \multicolumn{2}{|l|}{$n=145$} \\
\hline Accurate & $130(89.7 \%)$ \\
\hline Inaccurate & $15(10.3 \%)$ \\
\hline Cytological diagnosis (n) & Histological diagnosis (n) \\
\hline \multirow[t]{3}{*}{ Pleomorphic adenoma ${ }^{5}$} & Sialadenitis $^{2}$ \\
\hline & Tuberculosis $^{1}$ \\
\hline & Monomorphic adenoma ${ }^{2}$ \\
\hline \multirow[t]{2}{*}{ Lymphadenitis $^{4}$} & Pleomorphic adenoma ${ }^{3}$ \\
\hline & Monomorphic adenoma ${ }^{1}$ \\
\hline \multirow[t]{2}{*}{ Non neoplastic ${ }^{4}$} & Pleomorphic adenoma ${ }^{2}$ \\
\hline & Warthin tumor ${ }^{2}$ \\
\hline \multirow[t]{2}{*}{ Sialadenitis $^{2}$} & Pleomorphic adenoma $^{1}$ \\
\hline & Monomorphic adenoma ${ }^{1}$ \\
\hline
\end{tabular}

ity of $88.9 \%$ was observed. The specificity was $97.9 \%$, and the diagnostic accuracy was $95.8 \%$. The positive and negative predictive values were $93 \%$ and $96.7 \%$, respectively.

Serious complications such as hematoma, facial nerve injury or infection were not noted after performing FNAC. However, local inflammation was noted in 4 cases.

\section{Discussion}

Fine needle aspiration cytology has been widely accepted as an important diagnostic for the management of various lesions of the head and neck region. ${ }^{16}$ It has been claimed as a superior diagnostic modality by many authors and considered as safe and accurate with regards to complications and diagnosis respectively. ${ }^{9,17-19}$ On the other hand, some authors have argued that it plays a small role in clinical management because of the higher rates of false positives and false negatives and, ultimately, the patient has to undergo surgery. ${ }^{11}$ However, preoperative FNAC helps to differentiate between benign and malignant lesions and thus defines the extent of the surgery.

The sensitivity of FNAC in detecting malignancy was $89 \%$, which falls in a wide range of sensitivity reported in the literature, from as low as $27 \%$ to up to $97 \%$. $2,10,13,16,20,21$ The reason of this widely reported range of sensitivity is the dependence on the skills of the cytotechnologist performing FNAC and the expertise and experience of the pathologist to assess the adequacy and accurate examination of the provided specimen.

In our study, the specificity was reported to be $98 \%$, which is similar to what has been reported in the literature, ranging from $84 \%$ to $100 \%{ }^{2,10,13,16}$ The false negative FNAC results included a variety of lesions. Sampling error constitutes a common reason for false negative FNAC finding.

In the literature, the diagnostic accuracy of FNAC for parotid tumors has been reported as ranging from $84 \%$ to 97\%. ${ }^{2,10,16,22}$ Comparatively, in our study, it was reported as $95.8 \%$, which is within the given range. Specimens reported 
Table 5 False positives and false negatives

\begin{tabular}{|c|c|c|c|}
\hline \multicolumn{2}{|l|}{ False positives } & \multicolumn{2}{|l|}{ False negative } \\
\hline \multicolumn{2}{|l|}{$\mathrm{n}=\mathbf{3}$} & \multicolumn{2}{|l|}{$\mathrm{n}=5$} \\
\hline Cytological diagnosis (n) & Histological diagnosis (n) & Cytological diagnosis (n) & Histological diagnosis (n) \\
\hline \multirow[t]{2}{*}{ Mucoepidermoid carcinoma $^{1}$} & \multirow[t]{2}{*}{ Pleomorphic adenoma ${ }^{2}$} & \multirow[t]{2}{*}{ Pleomorphic adenoma ${ }^{2}$} & Malignant mixed tumor ${ }^{1}$ \\
\hline & & & Mucoepidermoid carcinoma ${ }^{1}$ \\
\hline \multirow[t]{3}{*}{ Myoepithelial carcinoma $^{1}$} & \multirow[t]{3}{*}{ Pleomorphic adenoma $^{1}$} & Warthin's tumor $^{1}$ & Carcinosarcoma $^{1}$ \\
\hline & & Lymph adenitis $^{1}$ & Lymphoma $^{1}$ \\
\hline & & Cyst $^{1}$ & Mucoepidermoid carcinoma $^{1}$ \\
\hline
\end{tabular}

Table 6 Comparison of histological results with preoperative cytology results

\begin{tabular}{|l|l|l|l|l|}
\hline \multicolumn{2}{|c|}{} & \multicolumn{2}{l|}{ Histological diagnosis } & Total \\
\hline \multirow{3}{*}{$\begin{array}{l}\text { FNAC } \\
\text { diagnosis }\end{array}$} & & Benign & Malignant & \\
\cline { 2 - 5 } & Benign & $145(\mathrm{TN})$ & $5(\mathrm{FN})$ & 150 \\
\cline { 2 - 5 } & Malignant & $3(\mathrm{FP})$ & $40(\mathrm{TP})$ & 43 \\
\hline Total & 148 & 45 & 193 \\
\hline
\end{tabular}

Abbreviations: FN, False negative; FNAC, fine needle aspiration cytology; FP, False positive; TN, True negative; TP, True positive.

to be nondiagnostic are a major drawback of FNAC, which has been reported to occur in between $\sim 5$ and $15 \%$ of the cases in the literature. In our study, only 8 aspirates $(4.1 \%)$ were found to be nondiagnostic. Failure to obtain an accurate and a representative specimen could be the result of poor localization of the target tissue and improper positioning of the needle in the necrotic, hemorrhagic or cystic area in the tumor. To reduce the chances of these errors and improve the diagnostic accuracy utilization of ultrasound has been advocated by various authors in the literature, ${ }^{23,24}$ although it was not used in our series.

In the present study, the overall concordance between the cytology specimen and the final histological diagnosis was found to be $85 \%$, which is comparable to the reported range in the literature. ${ }^{4,5}$ When the various pathological entities in patients included in our study were assessed, we found that $7.2 \%$ non-neoplastic (inflammatory) lesions such as sialadenitis were reported. In the literature, this proportion has been reported differently. Ashraf et al have reported 14\% non-neoplastic lesions. ${ }^{25}$ Jain et al reported $10 \%$ non-neoplastic lesions, ${ }^{26}$ whereas Singh Nanda et al published a study with $55.9 \%$ inflammatory lesions, which is the highest reported in the literature. ${ }^{27}$

Diagnosing pleomorphic, monomorphic adenoma and adenoid cystic carcinoma can be sometimes difficult due to varying, complex and overlapping morphological features. We had two cases of monomorphic adenoma which were reported as pleomorphic adenoma on the preoperative cytology. Similarly, a case of carcinosarcoma was labeled as Warthin tumor by FNAC. The percentage of false negatives in our study is $2.6 \%$, which is comparatively lower than the studies reported in the literature. ${ }^{5,16,28}$ On FNAC, two cases of pleopmorphic adenoma were misdiagnosed as mucoepidermoid and myoepithelial carcinoma, which could have happened because of lack of typical features and the presence of atypical cells on FNAC. ${ }^{29}$

Pleomorphic adenoma in 100 (91.7\%) of 109 cases were reported correctly within the range from 82 to $94 \%$ in the literature. ${ }^{5,25,26}$ According to Cohen et al, mucoepidermoid carcinoma is one of the most difficult and challenging lesions to diagnose cytologically. ${ }^{15}$ In our series, we were able to diagnose 21 out of 24 cases correctly.

The usefulness of FNAC in the diagnosis of lymphoma is limited without ancillary techniques, which is flow-cytometry. ${ }^{30}$ Cytomorphological features of these entities do not provide sufficient evidence for a rigorous diagnosis and classification. The final diagnosis of these entities depends upon the final histology due to the complexity of their classification and particular histological features. ${ }^{31}$ However, FNAC can be used as part of the initial management of these patients. ${ }^{32}$ In our series, we had 2 cases of lymphoma, out of which 1 case was diagnosed correctly.

Still, the role of FNAC in the diagnosis of parotid lesions has not been taken very well. ${ }^{33}$ Presence of hemorrhagic disease is the only relative contraindication to perform FNAC. $^{5}$ In our series, we had 2 cases of local inflammation which subsequently resolved. No other complication of nerve damage, hematoma or infection was observed.

Whether results obtained from FNAC can play a useful role in the clinical management of patients with parotid lesion or not is the most important question to be answered by the present study. The present study has demonstrated a variety of circumstances in which such data may be useful and valuable. For neoplastic lesions regardless of preoperative FNAC, surgical excision is recommended, but recognition of benign lesions beforehand may be of great benefit in avoiding inappropriate surgery and providing better counseling to the patient regarding the prognosis of the disease.

\section{Conclusion}

Our study suggests that preoperative FNAC plays a useful role in the accurate diagnosis of parotid tumors. It is a safe and effective diagnostic modality for the treatment of patients with parotid tumors. Fine needle aspiration cytology is a 
reliable, cost-effective, well tolerated and an easy procedure to perform. Moreover, it helps in preoperative differentiation of tumors, which may provide benefit in the preparation of both the surgeon and of the patient for an appropriate surgical procedure.

\section{Conflict of Interests}

The authors have no conflict of interests to declare.

\section{References}

1 Trandafir V, Trandafir D, Popescu E. Tumorile maligne ale glandelor salivare. J Chir (Paris) 2010

2 Chauhan N, Shah JA. Parotid Gland Tumours: Our Experience. Indian J Otolaryngol Head Neck Surg 2019;71(03):378-382

3 Namboodiripad PC. A review: Immunological markers for malignant salivary gland tumors. J Oral Biol Craniofac Res 2014;4(02):127-134

4 Alina I, Anca S, Tibor M, Simona M, Alina O, Mariana T. Efficacy of Fine Needle Aspiration Cytology in Diagnosis of Salivary Gland Tumors. Acta Med Marisiensis 2015;61(04):277-281

5 Ali NS, Akhtar S, Junaid M, Awan S, Aftab K. Diagnostic accuracy of fine needle aspiration cytology in parotid lesions. ISRN Surg 2011; 2011:721525

6 Ansari NA, Derias NW. Fine needle aspiration cytology. J Clin Pathol 1997;50(07):541-543

7 McGuirt WF, McCabe BF. Significance of node biopsy before definitive treatment of cervical metastatic carcinoma. Laryngoscope 1978;88(04):594-597

8 Allen EA, Ali SZ, Mathew S. Lymphoid lesions of the parotid. Diagn Cytopathol 1999;21(03):170-173

9 Lussier C, Klijanienko J, Vielh P. Fine-needle aspiration of metastatic nonlymphomatous tumors to the major salivary glands: a clinicopathologic study of 40 cases cytologically diagnosed and histologically correlated. Cancer 2000;90(06):350-356

10 López-Pazos P, Pérez-Sayáns M, Chamorro-Petronacci C, et al. Fine-needle aspiration cytology-efficacy in pre-surgical diagnosis of salivary gland tumors. Biomed Res 2018;29(13):2863-2866

11 Batsakis JG, Sneige N, el-Naggar AK. Fine-needle aspiration of salivary glands: its utility and tissue effects. Ann Otol Rhinol Laryngol 1992;101(2 Pt 1):185-188

12 Song IH, Song JS, Sung CO, et al. Accuracy of core needle biopsy versus fine needle aspiration cytology for diagnosing salivary gland tumors. J Pathol Transl Med 2015;49(02):136-143

13 Gudmundsson JK, Ajan A, Abtahi J. The accuracy of fine-needle aspiration cytology for diagnosis of parotid gland masses: a clinicopathological study of 114 patients. J Appl Oral Sci 2016; 24(06):561-567

14 Khan N, Afroz N, Agarwal S, et al. Comparison of the efficacy of the palpation versus ultrasonography-guided fine-needle aspiration cytology in the diagnosis of salivary gland lesions. Clin Cancer Investig J 2015;4(02):134
15 Cohen MB, Fisher PE, Holly EA, Ljung B-M, Löwhagen T, Bottles K. Fine needle aspiration biopsy diagnosis of mucoepidermoid carcinoma. Statistical analysis. Acta Cytol 1990;34(01):43-49

16 Atula T, Greénman R, Laippala P, Klemi PJ. Fine-needle aspiration biopsy in the diagnosis of parotid gland lesions: evaluation of 438 biopsies. Diagn Cytopathol 1996;15(03):185-190

17 Stewart CJ, MacKenzie K, McGarry GW, Mowat A. Fine-needle aspiration cytology of salivary gland: a review of 341 cases. Diagn Cytopathol 2000;22(03):139-146

18 Frable MAS, Frable WJ. Fine-needle aspiration biopsy revisited. Laryngoscope 1982;92(12):1414-1418

19 O'Dwyer P, Farrar WB, James AG, Finkelmeier W, McCabe DP. Needle aspiration biopsy of major salivary gland tumors. Its value. Cancer 1986;57(03):554-557

20 Wong DS, Li GK. The role of fine-needle aspiration cytology in the management of parotid tumors: a critical clinical appraisal. Head Neck 2000;22(05):469-473

21 Que Hee CG, Perry CF. Fine-needle aspiration cytology of parotid tumours: is it useful? ANZ J Surg 2001;71(06):345-348

22 Aversa S, Ondolo C, Bollito E, Fadda G, Conticello S. Preoperative cytology in the management of parotid neoplasms. Am J Otolaryngol 2006;27(02):96-100

23 Akbaş Y, Tuna EU, Demireller A, Ozcan H, Ekinci C, AKBAfi Y. Ultrasonography guided fine needle aspiration biopsy of parotid gland masses. Kulak Burun Bogaz Ihtis Derg 2004;13(1-2):15-18

24 Pratap R, Qayyum A, Ahmed N, Jani P, Berman LH. Ultrasoundguided core needle biopsy of parotid gland swellings. J Laryngol Otol 2009;123(04):449-452

25 Ashraf A, Shaikh AS, Kamal F, Sarfraz R, Bukhari MH. Diagnostic reliability of FNAC for salivary gland swellings: a comparative study. Diagn Cytopathol 2010;38(07):499-504

26 Jain R, Gupta R, Kudesia M, Singh S. Fine needle aspiration cytology in diagnosis of salivary gland lesions: A study with histologic comparison. Cytojournal 2013;10:5

27 Singh Nanda KD, Mehta A, Nanda J. Fine-needle aspiration cytology: a reliable tool in the diagnosis of salivary gland lesions. J Oral Pathol Med 2012;41(01):106-112

28 Zurrida S, Alasio L, Tradati N, Bartoli C, Chiesa F, Pilotti S. Fine-needle aspiration of parotid masses. Cancer 1993;72(08):2306-2311

29 David O, Blaney S, Hearp M. Parotid gland fine-needle aspiration cytology: an approach to differential diagnosis. Diagn Cytopathol 2007;35(01):47-56

30 Das DK, Francis IM, Sharma PN, et al. Hodgkin's lymphoma: diagnostic difficulties in fine-needle aspiration cytology. Diagn Cytopathol 2009;37(08):564-573

31 Jaffe ES. The 2008 WHO classification of lymphomas: implications for clinical practice and translational research. Hematology (Am Soc Hematol Educ Program) 2009;2009(01):523-531

32 Elkins CT, Wakely PE Jr. Cytopathology of "double-hit" nonHodgkin lymphoma. Cancer Cytopathol 2011;119(04):263-271

33 Bayramoğlu H, Düzcan E, Akbulut M, Topuz B. Infarction after fine needle aspiration biopsy of pleomorphic adenoma of the parotid gland. Acta Cytol 2001;45(06):1008-1010 